\title{
A Atuação Política de Mulheres na Ditadura Civil-Militar \\ Brasileira.
}

\author{
La Actuación Política de Mujeres en la Dictadura Civil-Militar Brasileña. \\ The Political Action of Women in the Brazilian Civil-Military Dictatorship.
}

\author{
Larissa Pinto Martins ${ }^{1}$
}

\begin{abstract}
Resumo
Este trabalho visa buscar a atuação política de mulheres durante o período ditatorial brasileiro (1964 a 1985). Em uma divisão entre militância de direita e de esquerda, elucidaremos a importância destas mulheres para a realização e efetividade do golpe civil-militar de 1964 e a resistência contra o mesmo, com uma breve problematização sobre como o exílio foi benéfico para as mulheres que militavam contra o regime, onde aprendiam novas formas de militância além da criação de um pensamento ou até de um reconhecimento feminista.
\end{abstract}

Palavras-Chave: Ditadura Civil-Militar; Mulheres; Política;

\section{Resumen}

Este trabajo visa buscar la actuación política de mujeres durante el período dictatorial brasileño (1964 hasta 1985). En una división entre militancia de derecha y de izquierda, elucidaremos la importancia de estas mujeres para la realización y efectividad del golpe civil-militar de 1964 y la resistencia contra lo mismo, con una breve problematización sobre como el exilio fue benéfico para las mujeres que militaban contra el régimen, donde aprendían nuevas formas de militancia además de la creación de un pensamiento o hasta de un reconocimiento feminista.

Palabras claves: Dictadura Civil-Militar; Mujeres; Política.

\section{Abstract}

This work aims at seeking the political action of women during the Brazilian dictatorial period (1964 to 1985). In a split between right-wing and left-wing activists, we will elucidate the importance of these women to the realization and effectiveness of the 1964 civil-military coup and the resistance against it, with a brief problematization of how exile was beneficial to women militants against the regime, where they learned new forms of militancy beyond the creation of a thought or even a feminist recognition.

Keywords: Civil-Military Dictatorship; Women; Politics.

\section{Introdução}

Ao longo da história do Brasil, as mulheres sempre foram minorias nas participações políticas, sejam elas de direita ou de esquerda. Quando falamos em política após o golpe de 1964 não é diferente, pois as mulheres também eram minorias dentro das organizações, sendo elas qual forem. Mesmo estando em números menores, as mulheres tiveram uma grande contribuição política no período militar, seja apoiando o golpe, como as mulheres de direita, da CAMDE (Campanha das Mulheres pela Democracia), ou em organizações de guerrilhas 
que atuavam contra o regime militar, sendo elas armadas ou não, e é isto o que quero mostrar com este artigo.

No que se refere à oposição ao regime ditatorial, grande parte destas organizações de militância atuava clandestinamente pois só era permitido dois partidos políticos, o ARENA Aliança Renovadora Nacional - o partido do governo, e o MDB - Movimento Democrático Brasileiro - , única oposição consentida.

Muitas das informações presentes neste artigo só foram possíveis graças a estudos de Marcelo Siqueira Ridenti (1990), que catalogou processos feitos contra mulheres de diferentes partidos ou organizações que militavam na época, estudando assim, suas atuações dentro de organizações de esquerda ou direita. Pelo fato dos partidos de esquerda serem organizações clandestinas, acaba, por ter mais processos do que os movimentos nacionalistas, sobre os quais quase não se encontra processos contra mulheres. Usando estes processos como fonte histórica podemos hoje ter conhecimentos mínimos, como por exemplo em qual área as mulheres estavam mais presentes.

Outro tipo de fonte histórica muito importante para pesquisas nessa área são as biografias e autobiografias, que muitos guerrilheiros de esquerda, historiadores ou jornalistas, acabaram produzindo logo ao final do regime. Por ser um marco histórico recente, também devemos considerar a historia oral como uma ótima fonte metodológica. Contudo, vale ressaltar que o presente artigo utiliza apenas fontes secundárias como bibliografias produzidas através destas fontes primárias.

Como argumenta Rollemberg (2007), o início dos anos 1960 foi um dos momentos da história do Brasil com a maior participação política da sociedade, que se organizava e atuava em diversos níveis. Dentro da esquerda, que é sempre enfatizada pela resistência, as mulheres faziam parte de guerrilhas, principalmente a armada. Já na direita, as mulheres tinham grande atuação política apoiando o regime, seja antes ou após o golpe de 1964.

A principal característica das mulheres que lutavam contra a ditadura, era a faixa-etária jovem intelectualizada, características que ao tratar deste período, início da década de 1960, também se enquadra como minoria perante a sociedade. Quando digo jovens intelectualizadas, me refiro a estudantes universitárias ou que já tinham algum formação, em sua maioria, professoras. Elas faziam parte de um grupo privilegiado, não por ser abastado de riqueza, mas por ter mais oportunidades culturais.

Analisando as características das mulheres de militância da direita, vemos que em sua maioria, são mulheres conservadoras, de classe média, mães, esposas, donas de casa, mulheres cristãs, que frequentam a igreja e tinham influência dentro da comunidade onde 
viviam. As mulheres da direita conservadora atuavam massivamente para o apoio ao golpe e contra o governo Goulart, usavam o catolicismo como uma arma anticomunista e organizavam caminhadas como a "Marcha Da Família Com Deus Pela Liberdade", marcha essa que mobilizava toda comunidade, inclusive o comercio e transporte, onde os comerciantes liberavam seus funcionários para marchar e facilitavam o transporte. Estas mulheres da direita conservadora tinham uma função de modificar a opinião pública de modo a torna-la favorável ao golpe de 1964. Afinal, era do interesse dos militares que houvesse uma espécie de chamamento popular contra o atual governo e contra a "ameaça" comunista. Desse modo, com o apoio da população, seria mais fácil oficializar o golpe militar, uma vez que o discurso era que ele seria o único instrumento que salvaria a pátria.

A Campanha da Mulher pela Democracia (CAMDE) tinha uma forte influência na sociedade. Dentro deste movimento, havia uma grande presença de mulheres da elite e ligadas a militares. Além disso, contavam com o apoio da grande mídia, como, por exemplo, o jornal $O$ Globo. A razão principal da criação da CAMDE era justamente para através destas mulheres o governo conseguir mobilizar de forma mais efetiva um apoio de grande parte da população para com os militares.

A CAMDE desenvolvia um papel de esclarecer para a sociedade a possível "ameaça comunista”, através de panfletos, reuniões públicas, protestos, debates sobre o assunto na televisão, organização de passeatas, e pressionando o comércio, iam moldando um pensamento nacionalista para a sociedade, criando um imaginário de que um regime militar seria preciso para que o Brasil não se tornasse uma "nova Cuba". Nesse sentido, René A. Dreifuss (2008) aponta que:

A CAMDE organizava reuniões de protesto, escrevia milhares de cartas aos deputados e, da mesma forma que o IBAD, pressionava firmas comerciais para retirarem seus anúncios dos jornais pró-João Goulart ou orientados pela esquerda e o trabalhismo. Distribuiria milhões de circulares e livretes preparados principalmente pelo complexo IPES/IBAD e produzia sua literatura própria visando às preocupações da dona-de-casa. Esses panfletos circulavam aos milhares por edição. Concentravam-se os esforços nas esposas de militares, dos membros dos sindicatos controlados pelo trabalhismo e de servidores públicos. (DREIFUSS, 2008. p.315)

Após o golpe de 64, as mulheres que antes mobilizavam a população a favor do regime militar, passaram a mobilizar a população para legitimar o novo regime. Tendo em vista que não seria apenas com força bruta e armamentos que os militares conseguiriam se manter durante tantos anos no poder. Eles tinham o apoio de uma grande parte da população, e isso havia sido conquistado por essas mulheres, mães e esposas, donas de casa. 
Em primeiro lugar, as mulheres ocupavam posições submissas na política e na sociedade brasileira, pelo menos até o final dos anos 60. A norma era a não participação das mulheres na política, exceto para reafirmar seus lugares de "mãeesposas-donas-de-casa", como ocorreu com os movimentos femininos que apoiavam o golpe militar de 1964 (RIDENTI, 1990, p.114).

Ridenti (1990) calcula que pelo menos $18 \%$ da guerrilha era formada por mulheres. Mesmo minoria dentro do movimento, as mulheres eram mais numerosas em grupos armados. $\mathrm{O}$ fato de mulheres estarem pegando em armas e lutando em grupos de esquerdas, estava quebrando estereótipos de mulher restrita ao lar ou submissa ao homem. Tornavam-se cada vez mais protagonistas, sendo assim, mesmo com o número de mulheres militantes sendo quase insignificante perto da quantidade de homens que militavam, ao colocarmos em um contexto social e temporal onde mulheres eram inferiorizada tanto na política quanto na sociedade, estas poucas mulheres que militavam, estavam fazendo com que as demais pudessem entender que tinham o poder de conquistar seus direitos na política assim como em outros espaços.

Dos processos analisados por Ridenti, viu-se que as mulheres politizadas eram aquelas que pegavam em armas e participavam ativamente das ações. Os outros processos contra as mulheres eram por terem algum tipo de parentesco ou ligação com homens militantes, mães, esposas, irmãs, ou por serem pegar em táticas de estratégias.

Pacificamente não havia como combater os as forças armadas dos militares, sendo assim, surge à necessidade de uma guerrilha armada. Além das pessoas que militavam nessa guerrilha, havia vários simpatizantes na luta, que ajudavam, não pegando diretamente em armas, mas de diversas outras formas. É muito difícil calcular um número exato destas pessoas, ou o gênero delas, porque eram organizações e alianças feitas às escondidas. Sabe-se que entre os simpatizantes, havia um grande número de mulheres, como as próprias mães e esposas dos militantes.

\section{O Exílio sob um novo olhar.}

Inicialmente, em 1964 após o golpe, muitas pessoas procuravam exílio, com isso, muitas mulheres saíam exiladas como companheiras, mães e filhas de perseguidos políticos. Após, 1968, com o AI-5, grande parte das mulheres exiladas acabavam saindo do país por serem perseguidas políticas pela sua atuação contra o regime e seu envolvimento com organizações de esquerda.

Meu objetivo ao problematizar o exílio como uma forma de aproveitamento e crescimento pessoal das mulheres que foram exiladas, se dá justamente por, fora do Brasil, 
muitas mulheres terem contato com novos pensamentos e conhecido novos métodos de militância, assim como aprimorado sua própria forma de guerrilha. Como argumenta Céli Regina Jardim Pinto:

Tínhamos, portanto, na Europa e nos Estados Unidos, cenários de grande efervecência política de revolução de costumes, de radical renovação cultural, enquanto no Brasil o clima era de ditadura militar, repressão e morte. Mesmo assim (...) surgiu e se desenvolveu o movimento feminista. (PINTO, C. R. J. 2003).

Com o Exílio, grande parte das mulheres exiladas começaram a familiarizar-se com pensamentos e ideais feministas antes não conhecidos. E, assim, acabaram por perceber a existência do machismo dentro da guerrilha apenas quando já estavam no exílio. Voltavam para o Brasil, com uma nova maneira de militância, auxiliando, anos depois, o movimento feminista no Brasil.

O destino das mulheres exiladas em grande parte era a Europa, o que propiciava uma grande concentração de brasileiros na França. Paris foi uma das principais sedes de grupos denominados feministas, que buscavam expandir seus ideais, criando assim, ligações com as brasileiras que lá foram buscar exílio. Segundo Céli R. J. Pinto,

Em Paris, no entanto, fervilhavam na época as ideias do movimento autônomo de mulheres, que viam a luta de classes e a luta pela liberação das mulheres como duas questões distintas, que não podiam ser subsumidas uma à outra. (PINTO, C. R. J. 2003).

Contudo, a reação dos homens exilados com esses novos pensamentos libertários não foi das melhores, muitos proibiam suas companheiras a participarem de reuniões de cunhos feministas alegando que estes seriam assuntos de pequeno-burguês, que as desvirtuariam da luta maior.

\section{A guerrilha e o feminismo.}

A militância feminina na esquerda, seja ela armada ou não, não pode ser enquadrada especificamente enquanto uma militância feminista. Não ao menos nos primeiros anos que sucederam ao golpe, uma vez que o contexto histórico era de repressão e censura, o feminismo não era uma realidade para o Brasil. Contudo, foram anos de avanços e conquistas femininas que tomaram força de 1975 a 1985 e, que em outras circunstancias, poderiam ser consideradas conquistas feministas. 
Só no exterior que a maioria das mulheres das organizações de esquerda nos anos 60 e 70 passaram a adquirir uma consciência explicitamente "feminista", da especificidade da condição de mulher na própria luta política e cotidiana, questionando um certo "machismo" no interior das próprias organizações políticas (machismo cujo grau variava conforme a organização. (RIDENTI. 1990. p. 118).

Como aponta Ridenti, dentro dos movimentos de guerrilhas anteriores ao exílio, não havia discussões ou reivindicações feministas. O que acaba justificando o porquê do feminismo no Brasil ter crescido entre 1975-85, momento de retorno das militantes exilidas para o Brasil.

As mulheres de esquerda não percebiam o machismo estruturado no sistema de militância antes do exílio, pois pouco se conhecia sobre o movimento feminista dentro do Brasil anterior a esta data. Tratavam o feminismo como 'coisa de pequeno burguês' afinal, dentro da guerrilha, a única coisa que importava era acabar com o regime militar inserido no país.

Uma forma de machismo dentro das organizações políticas de guerrilhas, era a forma como a guerrilheira era tratada entre os homens. Criava-se um estereótipo da mulher de organizações como a guerrilha armada, que por serem mulheres mais fortes e pegarem em armas, seriam mulheres feias. Ao contrário das que militavam em organizações mais pacíficas. Em geral, as mulheres da guerrilha armada eram as mais ativas. Além disso, uma mulher que militava na guerrilha armada, nunca seria tão bem vista como um homem que militava na mesma guerrilha.

Utopicamente, a ideologia da revolução era voltada para a não diferenciação entre homens e mulheres na militância, pois todos estariam a serviço da revolução e seriam soldados, independentemente do sexo. Mas havia uma dificuldade de ser mulher em um meio onde a grande maioria é de homens, onde as vozes femininas acabavam não sendo ouvidas ou negligenciadas pelo fato de serem mulheres. Eram tiradas de cargos altos como as organizações das guerrilhas por ser considerada "emocionalmente instável", mesmo que as mulheres fossem de máxima importância para a obtenção de informações fundamentais na organização dos combates.

Muitas mulheres acabavam usando da sensualidade para seduzir generais, gerentes de bancos, entre outros, para assim conseguir informações, fazer levantamentos de dados para a preparação de roubos ou sequestros. Os generais, banqueiros, homens em gerais eu diria, não achavam que uma mulher fosse alguém a quem precisasse temer, em muitos casos, eram seduzidos por mulheres e que por aparentarem ser inofensivas, passavam a elas muitas 
informações como horários, locais, pessoas, qualquer tipo de informação que juntas acabavam ajudando a organização das guerrilhas a planejarem a próxima ação.

Acabavam sendo negligenciadas até mesmo pelos seus companheiros de luta, por acharem que mulheres fossem inofensivas, deixavam-nas sozinha com estes homens, de modo que, se algo desse errado, elas não teriam escapatórias ou algum apoio para fuga. Dentro das guerrilhas armadas, quando uma mulher conseguia um fuzil, era como uma grande conquista pessoal, mesmo que para elas restassem as armas mais comuns, ao contrário dos homens que costumavam ficar com as melhores.

Como argumenta Wolff (2007), a militância nesses grupos era vista como algo "viril", que exigia coragem e determinação, desprendimento e espírito de sacrifício, qualidades vistas em nossa sociedade como masculinas. Sendo assim, as mulheres eram deixadas em segundo plano justamente por não possuírem esta virilidade.

Mas como vimos anteriormente, a participação das mulheres dentro da luta armada quebrou o mito de sua passividade que era estereotipado pela sua falta de virilidade. Todavia, as mulheres que mantinham uma aparência masculinizada eram mais respeitadas dentro da guerrilha. Em treinamentos, as mulheres masculinizadas eram melhore treinadas do que as mulheres mais femininas, que acabavam recebendo um treinamento menos intensivo.

\section{Conclusão}

As mulheres que participaram de guerrilhas durante o regime militar no Brasil, não se contentaram com o papel da esposa, dona de casa, provedora e enfermeira dos homens. Fizeram-se presente dentro das guerrilhas, seja pegando em armas, seja conseguindo informações para auxiliar possíveis ações. Não negligenciando as mulheres que atuaram politicamente a favor do regime, como as mulheres da CAMDE, que mobilizavam uma grande população para apoiar os militares, sem elas, possivelmente o regime não teria se mantido por tanto tempo no poder.

Concluo este trabalho, ressaltando a importância da visibilidade das mulheres em meios políticos, onde geralmente só são lembradas as participações de homens. A atuação política destas mulheres, por menor que tenha sido já que estavam em minoria perto da quantidade de homens envolvidos, fez a diferença durante o período ditatorial. Por isso dá importância de estudar suas atuações, contribuições e feitos. 


\section{Referências}

DREIFUSS, René Armand. 1964: a conquista do Estado: ação política, poder e golpe de classe. Petrópolis, RJ: Vozes, 2008.

PINTO, Céli Regina Jardim. O novo feminismo nasce na ditadura. In: Uma história do feminismo no Brasil. São Paulo: Editora Fundação Perseu Abramo, 2003. - Coleção História do Povo Brasileiro.

RIDENTI, Marcelo Siqueira. As mulheres na política brasileira: os anos de chumbo. Tempo Social; Rev. Sociol. USP, São Paulo, 1990. P. 113-128.

RIOS, Flavia. A trajetória de Thereza Santos: comunismo, raça e gênero durante o regime militar. Revista do Programa de Pós-Graduação Em Sociologia da USP, São Paulo, 2014. P.73-96.

ROLLEMBERG, Denise. "Memórias no exílio, memórias do exílio". FERREIRA, Jorge; AARÃO REIS, Daniel. (Orgs.). As Esquerdas no Brasil. Revolução e democracia (1964...). Vol. 3. Rio de Janeiro: Civilização Brasileira, 2007.

WOLFF, Cristina Scheibe. Feminismo e configurações de gênero na guerrilha: perspectivas comparativas no Cone Sul, 1968-1985. Revista Brasileira de História. São Paulo. 2007. p. 1938 . 